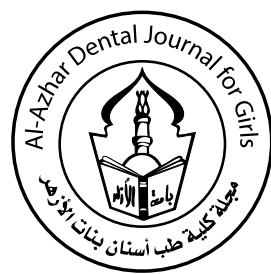

\title{
Influence of Henna Addition on The Flexural Strength of Acrylic Denture Base Material: An In Vitro Study
}

\author{
Mohammed M Gad ${ }^{(1)}$, Ahmed Rahoma ${ }^{(2,3)}$, Amal Nawasrah ${ }^{(1)}$, Mahmoud M Ammar ${ }^{(4)}$
}

Codex : 32/1807

azhardentj@azhar.edu.eg

http://adjg.journals.ekb.eg

\section{KEYWORDS}

Acrylic denture base, henna,

Polymethyl methacrylate,

flexural strength.

\begin{abstract}
Purpose: The purpose of this study was to evaluate the flexural strength of the acrylic denture base material modified with different concentrations of henna. Materials and Methods: Sixty heat polymerized acrylic resin specimens were fabricated in dimensions $65 \times 10 \times 2.5 \mathrm{~mm}$ according to ADA specifications \#12. Specimens were divided according to henna concentrations into 6 groups. One control group without henna addition while the other five groups were processed by adding henna in concentrations $1 \%, 2.5 \%, 5 \%, 7.5 \%$ and $10 \%$ of acrylic powder. After processing, specimens were finished, polished, and stored in distilled water at $37^{\circ} \mathrm{C}$ for $48 \pm 2$ hours prior to testing. The three-point bending test was used to measure the flexural strength using universal testing machine. The morphology of the fractured specimens was studied under a scanning electron microscopy (SEM). The independent sample t-test was used and $p \leq 0.05$ was considered statistically significant. Results: The flexural strength significantly decreased with henna addition to PMMA denture base material $(P<0.05)$, and this decrease was in proportional to henna concentrations. Conclusion: The flexural strength of acrylic denture base material negatively was affected by henna addition.
\end{abstract}

\section{INTRODUCTION}

Denture stomatitis (DS) is an inflammation of the mucosa under the complete denture base ${ }^{(1)}$. Treatment of DS includes adjusting the existing denture and follow oral hygiene instructions. The trend now is to prevent DS by using different materials including probiotics used locally contacting the mucosa and part of it will be swallowed and get

1. Lecturer, Department of Substitutive Dental Sciences, College of Dentistry, Imam Abdulrahman Bin Faisal University, P.O. Box 1982, Dammam 31411, Saudi Arabia

2. Lecturer, Department of Dental Biomaterials, College of Dentistry, Al-Azhar University, Assiut Branch, P.O. Box 11117, Egypt.

3. Assistant Professor, Department of Restorative Dental Sciences, College of Dentistry, Imam Abdulrahman Bin Faisal University, P.O. Box 1982, Dammam 31411, Saudi Arabia

4. Assistant Professor of Removable Prosthodontics, Faculty of Dental Medicine, Al-Azhar University, Assiut Branch. Egypt 
systemic effect ${ }^{(2)}$. Recently, more attention has directed toward the incorporation of novel antimicrobial agents ${ }^{(3,4)}$ and antimicrobial polymer added to Polymethyl methacrylate (PMMA) to decrease candida adhesion and growth on the denture bases (3,5). Amongst, henna has approved to be antifungal agent against Candida albicans ${ }^{(3,6)}$. Henna is a naturally occurring plant that is mainly used for coloring the hair and hands. In a recent review of the pharmacological effect of henna, it was found that it has anti-inflammatory, antimicrobial, antioxidant, and burn wound healing properties ${ }^{(7-9)}$.

In addition to the effect of antifungal agents, many factors that affect Candida adhesion and biofilm formation on acrylic surfaces have been described, among them surface roughness and hardness ${ }^{(10)}$. The surface properties of any denture base material are of particular concern as studies of these materials have shown a direct link between surface roughness, the accumulation of plaque and adherence of Candida Albicans ${ }^{(11)}$. The surface properties of acrylic resin can be affected by hardness, which is characteristic of the ease of finishing the material as it is resistant to in-service scratching during cleansing ${ }^{(12)}$. Therefore, study conducted to evaluate the effect of henna addition on the surface properties of PMMA and the results showed that the tested properties were adversely affected with more than $2.5 \%$ concentrations $^{(13)}$.

Denture base acrylic resins are subjected to different stresses. Repeated masticatory forces lead to fatigue phenomena intraorally, resulting in fracture. Alternatively, flexural strength of a material is a measure of stiffness and resistance to fracture and it can be measured and interpreted by various tests. PMMA resin is the material of choice for fabrication of a denture base, even though fracture is known to occur during function due to its poor flexural properties ${ }^{(14)}$. Therefore, additives effect preferably improve or at least keep the original flexural strength rather than weaken the modified material.
As noticed from the previous researches ${ }^{(3,6)}$ although addition of henna to PMMA has antimicrobial advantage and could be effective in controlling Candida albicans proliferation on the denture surface, ${ }^{(3)}$ we should also be concerned about its effects on the physical properties. Thus far, previous studies ${ }^{(3,6)}$ have been conducted to investigate the effect of henna addition on the surface properties. However, there has not been any study investigating mechanical properties of PMMA/henna composite. Since the flexural strength is a proper test for the evaluation denture base material strength ${ }^{(15)}$, this study was done to evaluate the effect of henna addition on the flexural strength of PMMA denture base material. The hypothesis of the present study was the flexural strength of PMMA denture base material will be affected after henna addition.

\section{MATERIALS AND METHODS}

Heat polymerized acrylic resin plates were fabricated according to ADA specifications \#12 for denture base polymer ${ }^{(15)}$. Custom metal molds in dimensions $65 \times 10 \times 2.5 \mathrm{~mm}$ were waxed up to fabricate 60 wax specimens which invested in type III dental stone (GC Fujirock EP) within the flask (61B Two Flask Compress, Handler Manufacturing, USA). After stone setting, flasks were placed into wax elimination machine for 10 minutes to melt away all wax creating mold spaces. When stone surfaces were warm, a separating medium (Isolmajor, Major Prodotti Dentari SPA, Italy) was applied. Specimens were divided according to henna concentrations into 6 groups (table 1).

Table (1) Specimens grouping and specifications according to henna concentrations

\begin{tabular}{|c|c|c|c|c|c|}
\hline Group & Code & $\begin{array}{c}\text { Polymer } \\
\text { conc. Gm }\end{array}$ & $\begin{array}{c}\text { Henna } \\
\text { conc. gm }\end{array}$ & Total & $\begin{array}{c}\text { Sample } \\
\#\end{array}$ \\
\hline $0 \%$ & Control & 100 & 0 & $100 \mathrm{gm}$ & 10 \\
\hline $1 \%$, & A & 99 & 1 & $100 \mathrm{gm}$ & 10 \\
\hline $2.5 \%$, & B & 97.5 & 2.5 & $100 \mathrm{gm}$ & 10 \\
\hline $5 \%$, & $\mathrm{C}$ & 95 & 5 & $100 \mathrm{gm}$ & 10 \\
\hline $7.5 \%$ & $\mathrm{D}$ & 92.5 & 7.5 & $100 \mathrm{gm}$ & 10 \\
\hline $10 \%$ & $\mathrm{E}$ & 90 & 10 & $100 \mathrm{gm}$ & 10 \\
\hline
\end{tabular}


Yamani henna (Harazi) was weighted using an electronic balance to be added in concentrations $0 \%$, $1 \%, 2.5 \%, 5 \%, 7.5 \%$, and $10 \mathrm{wt} \%$ of acrylic powder (Major base 20, Major Prodotti Dentari SPA, Italy) and then added and mixed separately. First, the mix was done manually using conventional mortar and pestle with gentile hand pressure. The PMMA/henna composite powder was stirred with electric mixer at a rotating speed of $400 \mathrm{rpm}$ at room temperature for 30 minutes to obtain a more homogenous and an equal distribution of henna powder. According to manufacturer recommendation, monomer polymer ratio was mixed and packed into mold spaces at a dough stage using pneumatic press and then pressed in the flask clamp for one hour before processing (bench curing). The flask was processed at $73^{\circ} \mathrm{C}$ for 90 minutes and then the temperature was increased to $100^{\circ} \mathrm{C}$ for 30 minutes in a thermal curing unit (KaVo Elektrotechnisches Werk GmbH, D-88299, Germany). The flasks were then kept for a minimum of 5 hours at room temperature to cool before deflasking. The retrieved specimens were finished and polished using a tungsten carbide bur (HM 79GX-040 HP; Meisinger, Centennial, CO 80112 , USA) with a thin cross cut at $18,000 \mathrm{rpm}$, followed by a coarse grain cylindrical rubber top bur for acrylic resin (Super Acrylic Polish, Long Dental, IL, USA) and then a fine grain cylindrical rubber top bur (Super Acrylic Polish, Long Dental, IL, USA) ${ }^{(16)}$. A digital caliper with a $0.01 \mathrm{~mm}$ accuracy (Neiko 01407A Electronic Digital Caliper) was used to check the proper dimension of specimens then stored in distilled water at $37 \mathrm{oC}$ for $48 \pm 2$ hours prior testing.

A common method to measure the flexural strength of denture base resins is the three-point bending test described in ISO standard $1567{ }^{(17)}$. Flexural strength was evaluated using a three-point bending test using a universal testing machine (Instron 8871; Instron Co., Norwood, MA, USA), done at room temperature. Specimen was placed horizontally on two vertical supports with $50 \mathrm{~mm}$ distance. Load was applied in the middle of each specimen with $50 \mathrm{Kgf}$ load with a crosshead speed of $5 \mathrm{~mm} / \mathrm{min}$ until the specimen fractured recording the fracture load. Flexural strength was calculated using the formula: $\mathrm{FS}=3 \mathrm{WL} / 2 \mathrm{bd}^{2}$, where $\mathrm{W}$ is the maximum load before fracture, $\mathrm{L}$ is the distance between supports $(50 \mathrm{~mm}), \mathrm{b}$ is the specimen width $10 \mathrm{~mm}$, and $\mathrm{d}$ is the specimen thickness $2.5 \mathrm{~mm}^{(18)}$.

\section{Scanning electron microscopy (SEM) analysis:}

After performing the flexural test, six fractured specimens were randomly selected from each group to study the morphology of the fractured surfaces. Cuts were made $5 \mathrm{~mm}$ away from the fracture line underwater cooling. A gold coating was applied using a sputter coating machine (Quorum, Q150R ES, UK) to overcome the non-conductive nature of the material. The surface of the specimens and the fractured cross- section were examined by SEM (FEI, ISPECT S50, Czech Republic). The acceleration voltage used to perform the SEM evaluation was set at $20 \mathrm{kV}$ with a working distance of $\sim 10 \mathrm{~mm}$ and a 3.5 spot size. The specimens were mounted on a metallic stub using double-sided adhesive tape. For better visual inspection, images were taken at different magnifications (x100, ×500, ×1000, $\times 2000, \times 4000, \times 5000)$ so that important features could be observed to determine the nature of the failure. Compact and smooth surface fields present brittle fracture modes, while a rough and jagged appearance presents intermediate (brittle to ductile) fracture modes (Figs 2).

Statistical data analysis was performed using SPSS version 20.0 (IBM, USA). The results of the flexural strength is shown as arithmetic mean and standard deviation (SD). In comparisons with the control group, an independent sample t-test used. A $p$-value $\leq 0.05$ was considered a statistically significant. 


\section{RESULTS}

Table 2. Mean values, $S D$, and P-values of flexural strength (MPa) of tested specimens

\begin{tabular}{|c|c|c|c|c|c|c|}
\hline Group & Control & A & B & C & D & E \\
\hline Mean \pm SD & $87.23 \pm 5.02$ & $77.94 \pm 6.32$ & $65.34 \pm 8.94$ & $54.72 \pm 6.04$ & $40.43 \pm 9.31$ & $29.07 \pm 9.34$ \\
\hline$P$-value & & $0.045^{*}$ & $0.000^{*}$ & $0.000^{*}$ & $0.000^{*}$ & $0.000^{*}$ \\
\hline
\end{tabular}

*Statistically significant.

The mean, $\mathrm{SD}$, and $P$-value of flexural strength of tested specimens are presented in table 2 and figure 1 . The results showed that the addition of henna significantly decreased the flexural strength of acrylic denture base $(P$-value $<0.05)$ in comparison to control group. In between henna modified groups (A-E), the flexural strength significantly decreased as the henna concentrations increased and the lowest flexural strength was recorded with group E.

Variation in the morphology of the fractured surface was assessed using SEM analysis. SEM images showed the surface characteristics of specimens with different concentrations of henna, the change in the fracture morphology ranging from rough surfaces (figure 2A, B) to smooth background with clusters and voids formation (fig 2. C-F). Figure $2 \mathrm{~A}$ representing conventional acrylic resin with irregular compact surface and show flake or sheet like structure of certain thickness while 2B show small voids with less irregularities. By increasing henna concentration, mirror like appearance background with some cluster formation which increased while going from B to E sample (fig. $2 \mathrm{C}-\mathrm{F}$ ). These voids may be formed due the formation of henna clusters, which increased as the henna concentration increased, leaving large voids. Ductile fracture mode (i.e., rough surface with uniform distributed lamellae) Fig. 2A which changed by henna addition to less random lamellae with appearance of small henna clusters fig. 2B represent intermediate form of fracture (i.e., jagged and less rough appearance). Brittle fracture mode (i.e., smooth or mirror like appearance background) mostly demonstrated as shown in fig. $2 \mathrm{C}-\mathrm{F}$ in addition to the increased henna cluster in size more the resin.

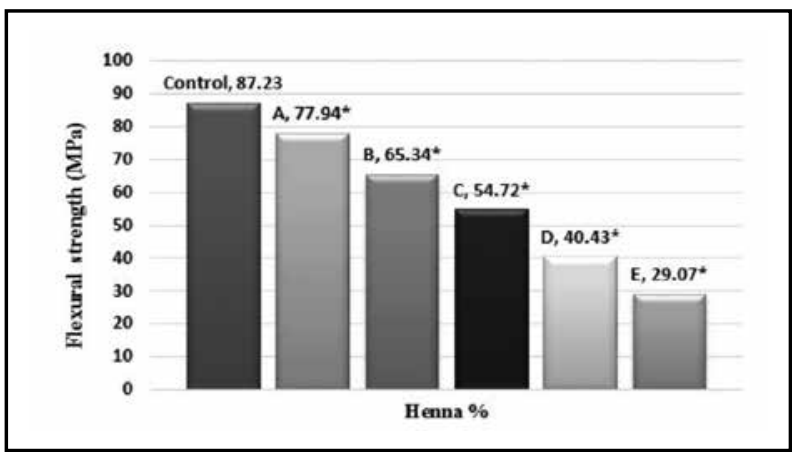

Fig. (1) Mean values of flexural strength of tested groups

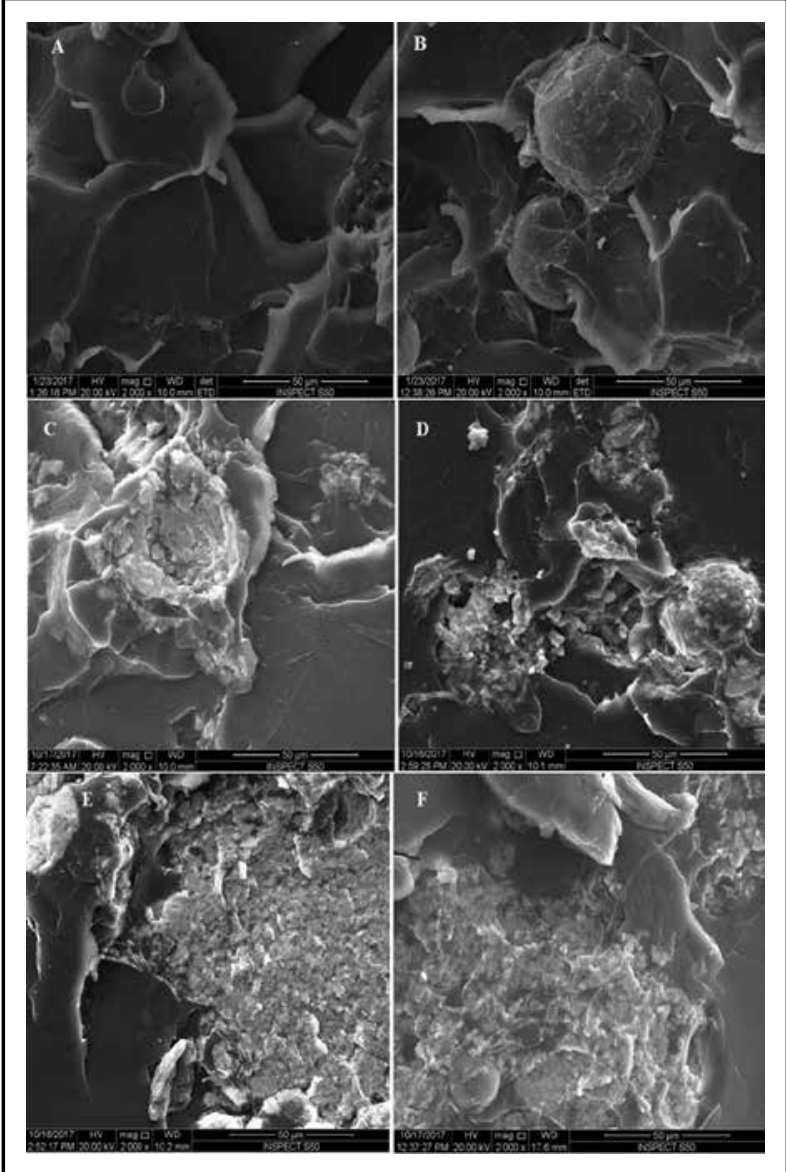

Fig. (2) Representative SEM images of tested specimens. A) Control group ; B) $1 \%$ henna; C) $2.5 \%$ henna; D) $5 \%$ henna; E) $7.5 \%$ henna; F) $10 \%$ henna. 


\section{DISCUSSION}

The study of the incorporation of antimicrobial agents into acrylic resins may represent a viable alternative to control the development of oral infections and improve the oral health of denture wearers. The construction of a denture base with an antimicrobial effect would be a remarkable achievement ${ }^{(3)}$. At the same time, the physical properties should not be unduly altered ${ }^{(13)}$. It seems that addition of henna to PMMA for antimicrobial activity would be beneficial but it should be performed under particular care and after evaluation of its effect on the physical properties of the acrylic resin.

The flexural strength of denture base resin is considered the primary mode of clinical failure particularly during which a bending force was applied to the denture during mastication ${ }^{(19)}$. The flexural strength test is a mixture of compressive, tensile, and shear strengths, this test reflects its rigidity and fracture resistance ${ }^{(19,20)}$. These characteristics of strength are important to a longer denture material's clinical service life, particularly having adequate mechanical cleansing ${ }^{(21)}$. In view of these requirements, PMMA denture base material modified with henna powder was evaluated for its flexural strength. The hypothesis of the present study was accepted since the flexural strength of acrylic denture base material was affected after henna additions as antifungal agent.

Based on the results of this study, adding henna at any concentration to acrylic denture base material has a significant decreasing effect on the flexural strength. This decrease may be attributed to the effect of this additive to PMMA denture base material since it acts as an interfering factor in the integrity of the polymer matrix ${ }^{(22,23)}$. Moreover, this decrease in flexural strength could be explained on that; the addition of henna causes these particles to aggregate (fig. $1 \mathrm{C}$-E) which can act as stress concentrating areas in the matrix ${ }^{(24)}$. The aggregated henna particles could lead to void formation from entrapped air and moisture and incomplete wetting of the particles by the resin ${ }^{(25)}$.
On the other hand, one of the problematic issues in incorporating henna into PMMA is pertained to lack of chemical bond between henna and PMMA resin matrix ${ }^{(23,26)}$. The other reason may be that the adverse effect of added henna on the degree of conversion which in turn leads to increase in the level of residual unreacted monomer that acts as plasticizer ${ }^{(25,27)}$. Accordingly, we can inferred that finding out more appropriate substances as coating or coupling agent between henna and resin matrix, alleviating it's deleterious effect on mechanical properties and not affecting its antifungal effect is hopeful.

It is noteworthy that the amount of additives is of critical importance. In previous study ${ }^{(13)}$, the hardness was significantly decreased with henna concentration of $2.5 \%$ and more, while it has insignificant decrease of hardness with $1 \%$ henna. According to the results of the present study, when henna exceeded a particular percentage (2.5\%), PMMA/henna composite decreased the flexural strength values dramatically. The decrease above this amount may be attributed to the fact that the maximum saturation of the matrix formation between PMMA and henna occurred at concentrations of $2.5 \mathrm{wt} \%{ }^{(13,28)}$.

Many studies ${ }^{(27,29,30)}$ have suggested antifungal agents (silver, titanium, or silica nanoparticles) addition to PMMA denture base resin and studied their effects on the effect on the flexural strength and reported that, the effect on flexural strength of PMMA depends on the filler concentrations. Moreover, the obtained flexural strength values at concentrations of $0.5 \%$ and $1 \%$ by weight into acrylic resin denture base adversely affected the mechanical properties of the polymerized material and flexural strength values decreased with increase in nanoparticles concentration ${ }^{(27,29,30)}$. The results of this study are consistent with previous reports regarding the decrease of the flexural strength value with the increase of the concentration of the antimicrobial agents added to the acrylic resin ${ }^{(27,29-31)}$.

It was reported that the minimum accepted flexural strength value according to ISO: 1567 
standard requirements is $65 \mathrm{MPa}{ }^{(17,32-35)}$. Although the flexural strength obtained in the tested groups were lower than the control group, the values were above the minimum flexural strength recommended for denture base materials for group A and group B while the values obtained for $\mathrm{C}, \mathrm{D}$, and $\mathrm{E}$ groups were lower than ISO: 1567 standard requirements. Therefore, based on the results of the current study, more than $2.5 \%$ henna deteriorate the mechanical properties of modified denture base resin.

Finally, it should be mentioned that this study was limited to just one brand of acrylic resin denture base and testing one property. Also, the specimen testing was in vitro and not mimic the oral conditions where repeated stress and wetted oral environment are present. Therefore, retesting the flexural strength of acrylic denture base material after some time-intervals to evaluate the effect of aging procedures on mechanical properties of PMMA/henna composite is recommended. Additionally, henna color may affect and alter the denture base color and esthetically unacceptable. To overcome the drawback of henna addition, there should be some ways to think about processing the acrylic resin; as to make the denture on two layers by adding henna just to the intaglio surface of the denture.

Clinically, adding henna to the acrylic resin should be done with caution as it may affect the physical properties of the acrylic resin inversely. However, the main concern regarding the trade-off between the antifungal activity of the henna and its effects on the mechanical properties of denture material should be balanced. Studying the minimum inhibitory concentration of henna as antifungal agent is necessitated. From the previous study, $1 \%$ henna showed a good level of antifungal activity and was statistically significant but the question remains whether it will be biologically significant. Also is possible that it will have negligible impact in vivo, or only be effective for a short duration. Therefore, it is important to determine the appropriate amount of henna that will create a balance between achieved properties.

\section{CONCLUSION}

Within the limitation of the current study, it could be concluded that the addition of henna powder to PMMA denture base material significantly decreased the flexural strength and this decrease was in proportion to henna concentrations.

\section{REFERENCES}

1. Yarborough A, Cooper L, Duqum I, Mendonça T, McGraw $\mathrm{K}$, Stoner L. Evidence regarding the treatment of denture stomatitis. J Prosthodont 2016;25:288-301

2. Ishikawa KH, Mayer MP, Miyazima TY, Matsubara VH, Silva EG, Paula CR, Campos TT, Nakamae AE. A multispecies probiotic reduces oral Candida colonization in denture wearers. J Prosthodont 2015; 24:194-9.

3. Nawasrah A. Antimicrobial denture. US Patent, 0367934 , 2017.

4. Al-Thobity AM, Al-Khalifa KS, Gad MM, Al-Hariri M, Ali AA, Alnassar T. In vitro evaluation of the inhibitory activity of thymoquinone in combatting Candida albicans in denture stomatitis prevention. Int J Environ Res Public Health 2017; 14:E743.

5. Compagnoni MA, Pero AC, Ramos SM, Marra J, Paleari AG, Rodriguez LS. Antimicrobial activity and surface properties of an acrylic resin containing a biocide polymer. Gerodontology 2014; 31:220-6.

6. Nawasrah A, AlNimr A, Ali AA. Antifungal effect of henna against Candida albicans adhered to acrylic resin as a possible method for prevention of denture stomatitis. Int J Environ Res Public Health 2016; 13:E520.

7. Abdulmoneim MA. Evaluation of Lawsonia inermis Linn. (Sudanese Henna) leaf extracts as an antimicrobial agent. Res J Biol Sci 2007; 2:419-23.

8. Singla S, Gupta R, Puri A, Bhardawaj VS, Roy S. Comparison of anticandidal activity of Punica granatum (Pomegranate) and Lawsonia inermis (Henna leaves): an in-vitro study. Int J Dent Res 2013; 1:8-13.

9. Muhammad HS, Muhammad S. The use of Lawsonia inermis Linn. (henna) in the management of burn wound infections. Afr J Biotechnol 2005; 4:934-7.

10. Lamfon, H, Porter SR, McCullough M, Pratten J. Formation of Candida albicans biofilms on nonshedding oral surfaces. Eur J Oral Sci 2003; 111, 465-71. 
11. Radford DR, Watson TF, Walter JD, Challacombe SJ. The effects of surface machining on heat cured acrylic resin and two soft denture base materials: A scanning electron microscope and confocal microscope evaluation. J Prosthet Dent 1997; 78:200-8.

12. Pinto Lde R, Acosta EJ, Távora FF, da Silva PM, Porto VC. Effect of repeated cycles of chemical disinfection on the roughness and hardness of hard reline acrylic resins. Gerodontology 2010; 27:147-53.

13. Nawasrah A, Gad MM, El Zayat M. Effect of Henna Addition on the Surface Roughness and Hardness of Polymethylmethacrylate Denture Base Material: An in vitro Study. J Contemp Dent Pract 2018; 19:732-8.

14. Consani RL, Folli BL, Nogueira MC, Correr AB, Mesquita MF. Effect of polymerization cycles on gloss, roughness, hardness and impact strength of acrylic resins. Braz Dent J 2016; 27:176-80.

15. Revised American Dental Association specification No. 12 for denture base polymers. J Am Dent Assoc 1975; 90:451-8.

16. Corsalini M, Boccaccio A, Lamberti L, Pappalettere C, Catapano S, Carossa S. Analysis of the Performance of a Standardized Method for the Polishing of Methacrylic Resins. Open Dent J 2009; 3:233-40.

17. Zappini G, Kammann A, Wachter W: Comparison of fracture tests of denture base materials. J Prosthet Dent 2003; 90:578-85.

18. Soygun K, Bolayir G, Boztug A. Mechanical and thermal properties of polyamide versus reinforced PMMA denture base materials. J Adv Prosthodont 2013; 5:153-60.

19. Chitchumnong P, Brooks SC, Stafford GD. Comparison of Three- and Four-Point Flexural Strength Testing of Denture-Base Polymers. Dent Mater 1989; 5: 2-5.

20. Jagger DC, Jagger RG, Allen SM, et al: An investigation into the transverse and impact strength of high strength denture base acrylic resins. J Oral Rehabil 2002; 29; 263-7.

21. Meng TR, Latta MA: Physical properties of four acrylic denture base resins. J Contemp Dent Pract 2005; 4:93-100.

22. Pesci-Bardon C, Fosse T, Madinier I, Serre D. In vitro new dialysis protocol to assay the antiseptic properties of a quaternary ammonium compound polymerized with denture acrylic resin. Lett Appl Microbiol 2004; 39:226-31.

23. Kanie T, Arikawa H, Fujii K, Inoue K. Physical and mechanical properties of PMMA resins containing gammamethacryloxypropyltrimethoxysilane. J Oral Rehabil 2004; 31:166-71.
24. Han Y, Kiat-amnuay S, Powers JM, Zhao Y. Effect of nano-oxide concentration on the mechanical properties of a maxillofacial silicone elastomer. J Prosthet Dent 2008; 100:465-73.

25. Arora P, Singh SP, Arora V. Effect of alumina addition on properties of poly-methyl methacrylate-a comprehensive review. Int J Biotech Trends Technol 2015; 5:1-7.

26. Khan MSLD, Heinrich G, Gohs U, Franke R. Structureproperty effects on mechanical, friction and wear properties of electron modified PTFE filled EPDM composite. Express Polymer Letters 2009; 266:39-48.

27. Shibata T, Hamada N, Kimoto K, Sawada T, Sawada T, Kumada H, Umemoto T, Toyoda M. Antifungal Effect of Acrylic Resin Containing Apatite-Coated TiO2 Photocatalyst. Dent Mater J. 2007; 26:437-44.

28. Kati FA, Al-Kaabi AF. Effect of oil paint addition on micro hardness of acrylic ocular prosthesis. Iraq Dent J 2016; 38 : 87-9.

29. Sodagar A, Kassaee MZ, Akhavan A, Javadi N, Arab S, Kharazifard MJ. Effect of silver nanoparticles on flexural strength of acrylic resins. J Prosthodont Res 2012; 56:1204.

30. Sodagar A, Bahador A, Khalil S, Shahroudi AS, Kassaee MZ. The Effect of $\mathrm{TiO} 2$ and $\mathrm{SiO} 2$ Nanoparticles on Flexural Strength of Poly(methyl methacrylate) Acrylic Resins. J Prosthodont Res 2013; 57: 15-9.

31. Casemiro LA, Martins CH, Pires-de-Souza FD, Panzeri H. Antimicrobial and mechanical properties of acrylic resins with incorporated silver-zinc zeolite - part I. Gerodontology 2008; 25:187-94.

32. Regis RR, Zanini AP, Della Vecchia MP, Silva-Lovato CH, Paranhos O, Freitas H, De Souza RF. Physical properties of an acrylic resin after incorporation of an antimicrobial monomer. J Prosthodont 2011; 20, 372-9.

33. Cunha TR, Regis RR, Bonatti MR, de Souza RF: Influence of incorporation of fluoroalkyl methacrylates on roughness and flexural strength of a denture base acrylic resin. J Appl Oral Sci 2009; 17:103-7.

34. Kul E, Alada $\breve{g}$ L I, Yesildal R. Evaluation of thermal conductivity and flexural strength properties of poly (methyl methacrylate) denture base material reinforced with different fillers. J Prosthet Dent 2016; 116:803-10.

35. Pfeiffer P, Rolleke C, Sherif L. Flexural strength and moduli of hypoallergenic denture base materials. J Prosthet Dent 2005; 93:372-7. 